letters

TO THE EDITOR

Please submit letters for the

Editor's consideration within

three weeks of receipt of the

Journal. Letters should ideally

be limited to 350 words, and

should be submitted either on

disk or by e-mail to:

Thomas.Allum@rcplondon.ac.uk

\section{Modern doctoring}

Editor - How brave of Dr McGouran and the Journal (JRCPL November/December 2000 , pp582-3) to risk the wrath of the godfathers of the cardiological Mafia. It is certainly time to question the concept of treating populations and not people, because what can be shown statistically to be right for a group is not always appropriate to the individual. If general physicians believed otherwise, they would presumably have specialised in public health. I have amazed managers by telling them that I follow guidelines and give treatments to my patients which I would not, however, have myself.

In the hospital where I work, there are each year several catastrophes of the type described by Dr McGouran. The staff are careful and caring; the treatment is given correctly by current standards, but occasionally kills patients who would otherwise not have died. I have observed an increase in cardiac rupture since the introduction of thrombolysis and I am informed that cardiologists accept this. I am sufficiently impressed by what I have seen that I personally would not allow infusion of streptokinase - I would take my chance with the disease and not risk a therapeutic death. I would have grave reservations about taking a statin, because of the high incidence of enzyme disturbances. I wouldn't be particularly happy about taking an ACE inhibitor either, because I don't enjoy coughing and because I have seen too many unexpected cases of renal failure caused by this class.

If we have reached the stage of having to practice medicine by guideline, there must be a question mark over why physicians are needed. Managers already have difficulty understanding what we do all day. 'Thinking about our patient's treatment' has always been an acceptable reply, but I wonder if 'following guidelines' will be as convincing?

PETER DAGGETT Consultant Physician Staffordshire General Hospital

Editor - McGouran (JRCPL November/ December 2000 pp582-3) illustrates the difficulty facing individuals deciding whether to accept thrombolysis, but does not provide a rational analysis. Ignoring non-fatal benefit (less LV dysfunction) and harm (minor stroke/major haemorrhage) a logical decision rests on the likelihood of avoiding death, independent of its cause. On average two deaths (three fewer coronary deaths, one treatment induced death) are avoided per 100 patients treated. This substantial chance of benefiting from a risk-free (benefit calculated is net) intervention gives much better odds than many of us accept playing the lottery. In practice it is difficult to be so dispassionate with haemorrhagic deaths easily identified but not those avoided by thrombolysis.

For long-term treatment we all recall patients receiving $\beta$-blockers complaining of lethargy but average quality of life is better than on placebo $^{1}$. The likely explanations for this apparent paradox are that patients feeling distinctly better on $\beta$-blockers do not complain or that many of the symptoms interpreted as adverse effects are non-pharmacological in origin ${ }^{2}$. As with thrombolysis we never know which patients on $\beta$-blockers extend their lives. Thus personal experience exaggerates the prevalence of adverse drug effects and diminishes any impression of benefit.

Given full information about the effects of treatment some patients would take daily medication for five years with a 1:50 chance of avoiding a coronary event ${ }^{3}$. Guidelines tell us which patients should be offered treatment but not all will accept. To help patients reach a logical decision consistent with their personal views about the various outcomes, doctors need to know an individual's chances of risk and benefit. The bias of personal experience necessitates information derived from clinical trials. In the rare situation where risk and benefit can be measured in the same outcome, eg death, the number needed to treat encapsulates all necessary information. Typically treatment reduces the risk of a number of unpleasant outcomes at the expense of a range of costs including financial, the inconvenience of regular treatment and minor troublesome or rare catastrophic adverse effects. Decision analysis ${ }^{4}$ may assist patients making such complex choices but we do not know whether they feel comfortable with the outcome or are likely to follow it long-term.

\section{References}

1 Grimm RH Jr, Grandits GA, Cutler JA, Stewart AL et al. Relationships of quality-of-life measures to long-term lifestyle and drug treatment in the Treatment of Mild Hypertension Study. Arch Int Med. 1997;157:638-48.

2 Meyer FP, Troger U, Rohl FW. Adverse nondrug reactions: an update. Clin Pharm Ther 1996;60:347-52

3 Nicholson K, Ramsay LE, Haq IU, Wallis EJ et al. Factors affecting the acceptance of drug therapy to prevent myocardial infarction. Br J Clin Pharmacol, 1999;47: 575-602.

4 Protheroe J, Fahey T, Montgomery AA, Peters TJ. The impact of patients' preferences on the treatment of atrial fibrillation: observational study of patient based decision analysis. Br Med J 2000; 320:1380-4.

PETER JACKSON

University Section of Clinical Pharmacology \& Therapeutics, Royal Hallamshire Hospital, Sheffield

Editor - Many of your readers will sympathise with Dr McGouran's indignation at mindlessness in modern medicine (JRCPL November/December 2000, pp582-3). Part of the problem arises because managers (and even some physicians) have acquired from surgeons the bad habit of confusing fatality with mortality. One would not expect a hospital fatality rate reduction of $20 \%$ in acute myocardial infarction to have an identifiable effect on mortality rates from coronary heart disease.

Another worry is the failure to include clinically important outcomes in the massive randomised controlled trials 
necessary to measure small effects. The logistics of such trials, may impede the recording of results other than short-term survival. Yet the rationale of thrombolysis for older patients with myocardial infarction, for example, includes the hope of saving cardiac muscle to reduce the subsequent risk of chronic heart failure - a state more miserable than many people realise.

Unfortunately, once a credible trial showing a reduction in fatality has been published, placebo-controlled trials to measure other neglected outcomes become impossible. Attempts to pursue Dr McGouran's implied question of how to identify which patients will benefit, require post hoc subgroup analyses and are usually forbidden, even though, if treated as hypothesis-generating rather than hypothesis testing, they may prove illuminating ${ }^{1}$. 'Trialists' have come to comprise a definable scientific specialty with a powerful statistical base. There are sound practical reasons for this, but if they cannot be persuaded to adapt their methods to ask the right questions, clinicians will be left without the right answers.

\section{Reference}

1 Rothwell PM, Warlow CP (on behalf of the European Carotid Surgery Trialists' Collaborative Group). Prediction of benefit from carotid endarterectomy in individual patients: a risk-modelling survey. Lancet 1999;353:2105-10.

\section{JOHN GRIMLEY EVANS} University of Oxford

\section{In response}

Editor - I am grateful to Dr Daggett for his comments. I have personally received a number of letters and e-mails since the article was published, many along the lines of his letter. All have supported my concern that 'evidence based medicine' pushes us into applying population proven treatments to individuals, and that individuals suffer as a consequence. None have endorsed the opposing view. I have noticed, however, that most of the writers are of my generation and I have been a consultant for 20 years.

Data described as 'evidence based' achieve scientific respectability, when all it means is that mathematical manipulation of the figures has produced a number previously agreed to indicate statistical significance. The important observation, as Professor Grimley Evans points out, is whether most patients will benefit from the treatment in one way or another, but evidence based analysis stops at the $p$ value, usually for a single outcome. It is easy to see, in these days of doctor bashing, litigation and guidelines, how the $p$ value offers a chance of a peaceful night's sleep, but first we have to forget that our primary responsibility as doctors is to our patients and not to ourselves.

Dr Jackson feels there is a better chance of benefiting from thrombolysis than winning the lottery. We should certainly hope for more favourable odds for our patients than ten million to one against, but the purpose of my paper was to question why we have moved in half a century from recommending treatment shown to benefit most patients to treatments shown in sophisticated trials to benefit only a tiny minority.

I suspect, as Dr Daggett points out, that many older physicians feel that they have been manoeuvred into prescribing drugs that they would not take themselves, and we should wonder whose puppets we have become.

RORY MCGOURAN Queen Elizabeth Hospital, Kings Lynn

\section{Neuromythology}

Editor - Thank you for publishing the views of Professor Tallis (JRCPL November/December 2000 pp563-7). This is a remarkably provocative article, although the pseudoscientific wrapping may have disguised the radical antiscientific nature of the underlying message.

Professor Tallis does not believe that the mind is a function of the physical phenomena occurring in the brain and he derides as neuromythology the currently limited but ever improving scientific approach to the understanding of intelligence and consciousness.

Many of his arguments are fallacious. The problem of deriving variety from monotonous regularity does not exist. There is nothing more monotonous than the binary code that forms the basis of all computer language, yet this code can be translated into a chess game adequate to beat all but the greatest masters.

He appears to suggest that the ability to do two things at once (avoid a bicycle whilst crossing the road) refutes any physically based theory of brain function. My cats can perform this task, possibly more dextrously than Professor Tallis, but how can this be? He does not believe conventional neuroscience can explain such actions, but reserves the magical characteristics of mind (and soul, whatever that is) for humans.

His assault on the neural theory of consciousness as savagely impoverished is quite breathtaking. Without providing any testable alternative, he locates consciousness not only outside the brain but apparently outside the physical world. I suppose this has a degree of internal consistency, in that there is no point in discussing in a scientific and rational way a belief which lies beyond the scientifically describable universe.

There is a problem whenever one tries to combine science and religion. Science in general and evolution in particular are highly convincing in their explanation of the observable universe, with no other rival in sight. Religion is not required to explain anything. I would refer interested parties to the same source as Professor Tallis' first reference - Daniel Dennett, and in particular his wonderful (if rather complex) book about evolution and the meaning of life ${ }^{1}$.

\section{Reference}

1 Dennett DC. Darwin's dangerous idea. London: Penguin, 1995.

JOHN MAIN Consultant Nephrologist Middlesbrough

\section{In response}

Dr Main's critique of my Fitzpatrick lecture asserts that I am hostile to science. As is made plain in the final paragraph of my paper, it does not follow from my belief that neuroscience cannot explain human consciousness, that I am anti-science or even anti-neuroscience. Given that I am the author of a large number of scientific papers, it would be very odd if I were. I have, moreover, written extensively - and passionately - in defence of science against its detractors ${ }^{1,2}$. What I oppose is scientism 